\title{
Tamsulosin versus Alfuzosin as medical therapy for ureteric stones
}

Piya B, Singh S K, Gurung R.

\begin{abstract}
Objectives: To evaluate and compare the efficacy of tamsulosin and alfuzosin as medical therapy in ureteric stones.

Patients and Methods: A total of 87 patients with ureteral stones of size $\leq 10 \mathrm{~mm}$ were randomly divided into 3 groups. Group I patients $(n-30)$ received $0.4 \mathrm{mg}$ of tamsulosin daily, group II patients $(n-29)$ received $10 \mathrm{mg}$ of alfuzosin daily and group III patients $(n-28)$ received no alpha blockers. All patients were given analgesia when needed. Follow up was done in weekly basis for 4 weeks.
\end{abstract}

Results: The mean stone size $(5.33 \pm 1.58,5.79 \pm 1.84,5.67 \pm 1.64)$ and age $(29.1 \pm 6.3,30.31 \pm 7.22,29.4 \pm 7.63)$ were comparable in each groups. The stone expulsion rate was $83.3 \%, 79.3 \%$ and $50 \%$ in group I, II and III respectively. The drugs related side effects reported by patients were mild and transient.

Conclusion: The use of tamsulosin and alfuzosin for the medical treatment of ureteric stones proved to be safe and effective and neither did have any significant benefits over the other. 